\title{
Research on Bending Performance and Engineering Application of Autoclaved Aerated Concrete Roof Panel
}

\author{
Guo-Wei ZHANG, Bo-Shan CHEN*, Hui WU, Wei XIAO
}

Beijing Higher Institution Engineering Research Center of Civil Engineering Structure and Renewable Material, Beijing University of Civil Engineering and Architecture, Beijing, China 100044

\author{
443783510@qq.com \\ ${ }^{*}$ Corresponding author
}

Keywords: Autoclaved Aerated Concrete, Engineering Application, Bending Performance.

\begin{abstract}
To investigate the seismic behavior of autoclaved aerated concrete (AAC) roof panels, the bending experiment of 4 AAC slabs for estimating the deflection and moment capacity was made. All specimens were placed under a test frame using monotonically increasing load till failure. The experimental results indicated that the stiffness and load-carrying capacity of AAC panels can meet the requirements of the roof panel. Reinforced AAC roof panels, which serve as a substitute for normal one can be used efficiently to provide a structurees horizontal diaphragm system while supporting the necessary gravity loads. The study in this paper can provide a reliable experimental basis for further analysis and engineering application of AAC roof panels in the future.
\end{abstract}

\section{Introduction}

\section{The Background}

Autoclaved aerated concrete (AAC), a form of cellular concrete, is a low-density product of calcium silicate hydrates in which the low density is obtained by the formation of macroscopic air bubbles, mainly by chemical reactions within the mass during the liquid or plastic phase. The thermal conductivity of AAC is 6 to $7.5 \%$ that of conventional concrete, making it energy-efficient. Because of its characteristic high internal porosity, AAC has very high sound absorption [1].

AAC can be used to make unreinforced, masonry-type units, and also factory-reinforced floor panels, roof panels, wall panels, lintels, beams, and other special shapes. These elements can be used in a variety of applications, including residential, commercial, and industrial construction. Reinforced wall panels can be used as cladding systems as well as load-bearing and non-load-bearing exterior and interior wall systems. Reinforced floor and roof panels can be used efficiently to provide a structurees horizontal diaphragm system while supporting the necessary gravity loads [2].
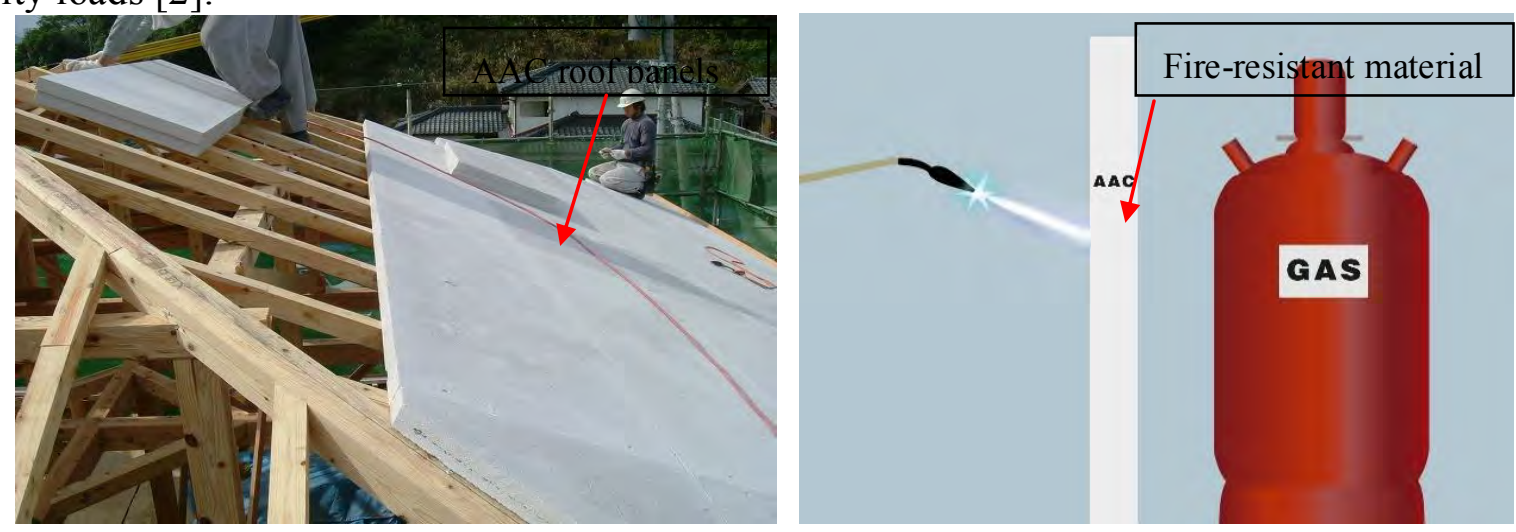

Fig. 1 Left: Roof Panel, Right: Fire-resistant Material

\section{Manufacture of AAC}

The raw materials are then batched by weight and delivered to the mixer. Measured amounts of 
water and expansive agent are added to the mixer, and the cementitious slurry is mixed. Steel molds are prepared to receive the fresh AAC. If reinforced AAC panels are to be produced, steel reinforcing cages are secured within the molds. After mixing, the slurry is poured into the molds. Within a few hours after casting, the initial hydration of compounds in the AAC gives it sufficient strength to hold its shape. The material is removed from the molds and fed into a cutting machine. After cutting, the aerated concrete product is transported to a large autoclave, where the curing process is completed. Autoclaving is required to achieve the desired structural properties and dimensional stability [3]. Overall steps in the manufacture of AAC are shown in Fig. 2

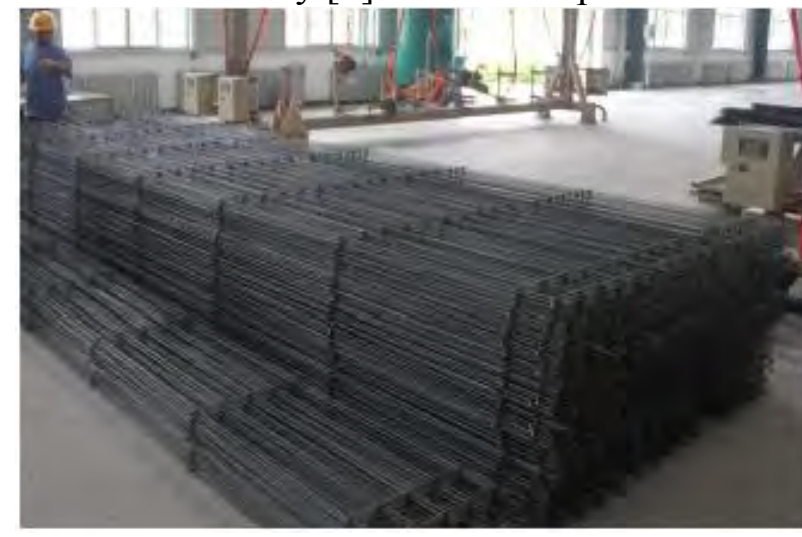

(a)Framework of steel reinforcement

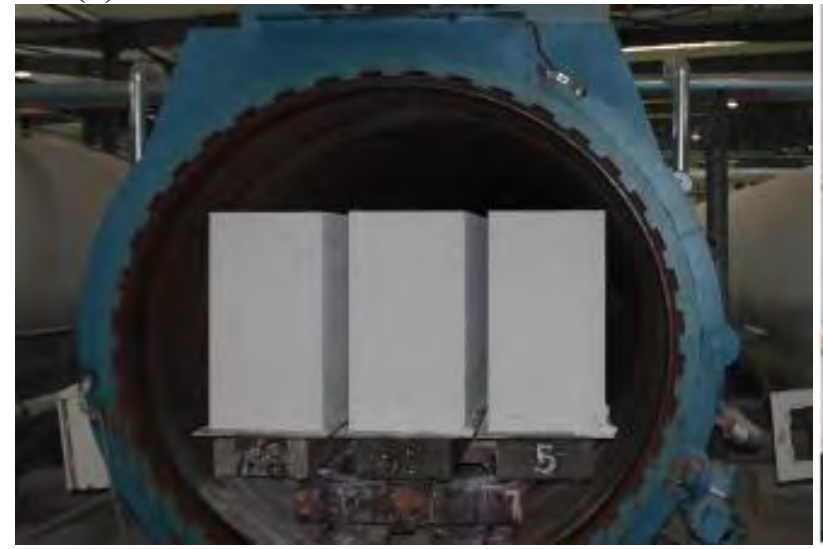

(c)Autoclaving AAC

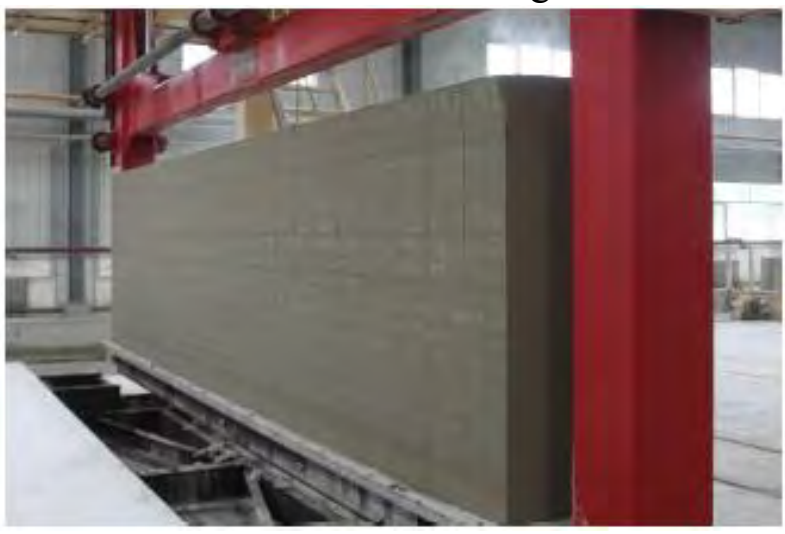

(b)Cutting AAC into desired

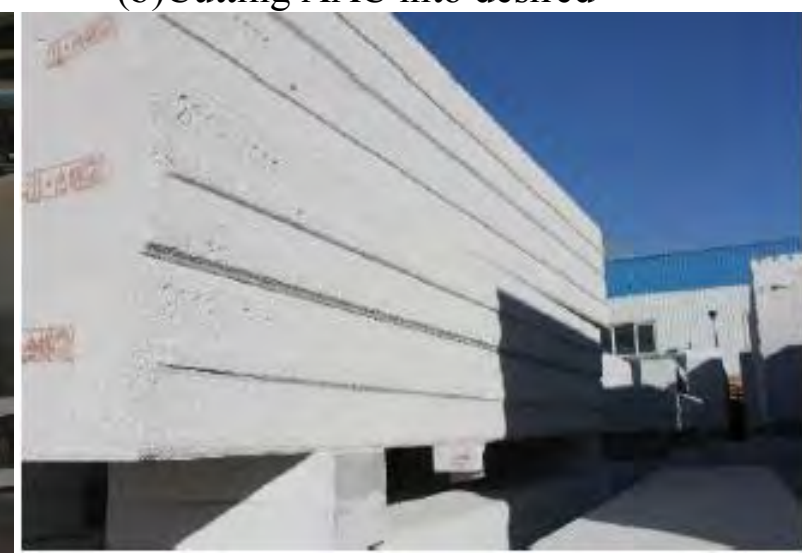

(d) Finished product of AAC

Fig. 2 Overall Steps in the Manufacture of AAC

AAC typically has one-sixth to one-third the density of conventional concrete, making it suitable for roof panels. All floor and roof anchors should be installed before placement of the panels, thus expediting panel installation.

\section{Research Significance}

Today, AAC prefabricated elements are gaining rapid acceptance in the China due mainly to increasing energy cost, environmental concerns, and the ease of construction using AAC elements. Although AAC is a well-recognized building material, still little research work has been done on China.-produced AAC products.

\section{Objectives}

The primary objectives of this research are to study the structural behavior of AAC elements used for roof panels as well as the engineering application and the following aims should be accomplished;

- To review the basic characteristics and structural applications of AAC;

- To observe a full-scale AAC roof paneles flexural performance under a four-point bending test and observe the failure mode;

- To recommend structural design procedures for factory reinforced AAC panels. 


\section{Experimental Procedure}

\section{Test Specimens}

In this investigation, a total of four specimens were designed and this study was performed on the following dimensions of $3600 \mathrm{~mm} \times 600 \mathrm{~mm} \times 150 \mathrm{~mm}$ size. The dry bulk density of the samples had been lowered to $500 \mathrm{~kg} / \mathrm{m} 3$. The 28-day mean strength of plain AAC was $3.5 \mathrm{MPa}$. The information of tested panels was shown in Table.1.

Tab. 1 Information of Tested Panels

\begin{tabular}{|c|c|c|c|c|}
\hline No. & $\begin{array}{l}\text { Dimension } \\
(\mathrm{mm})\end{array}$ & Dispose ways of bar & $\begin{array}{l}\text { Type of } \\
\text { slab }\end{array}$ & loading mode \\
\hline A & $3600 \times 600 \times 150$ & $\begin{array}{ll}\begin{array}{l}3 \Phi 6.5 \\
\text { (lower) }\end{array} & \text { (top)+6Ф6.5 } \\
\end{array}$ & B05 A3.5 & four-point loading \\
\hline B & $3600 \times 600 \times 150$ & $3 \Phi 6.5$ (top)+6Ф6.5 (lower) & B05 A3.5 & four-point loading \\
\hline $\mathrm{C}$ & $3600 \times 600 \times 150$ & $3 \Phi 6.5$ (top)+6Ф6.5 (lower) & B05 A3.5 & four-point loading \\
\hline $\mathrm{D}$ & $3600 \times 600 \times 150$ & $3 \Phi 6.5$ (top)+6Ф6.5 (lower) & B05 A3.5 & four-point loading \\
\hline
\end{tabular}

\section{Test Setup and Loading Procedure}

The experimental setup consists of loading beam, a vertical loading device to imitate gravity, and displacement transducer. The static load was applied by a hydraulic jack to the specimens through a wooden spreader beam. The four-point loading pattern was used to achieve the pure bending. The test device was shown as Fig.3. The slab was loaded with a loading rate of $0.2 \mathrm{kN} / \mathrm{s} \sim 0.5 \mathrm{kN} / \mathrm{s}$. The loading procedure was controlled by load before the cracking of the specimen. Then, all the specimens were loaded monotonically up to failure in few minutes. The specimen was considered to have failed when it's bearing capacity dropped to $85 \%$ of the maximum measured load. Observe the failure mode and give numbers to new cracks [4].
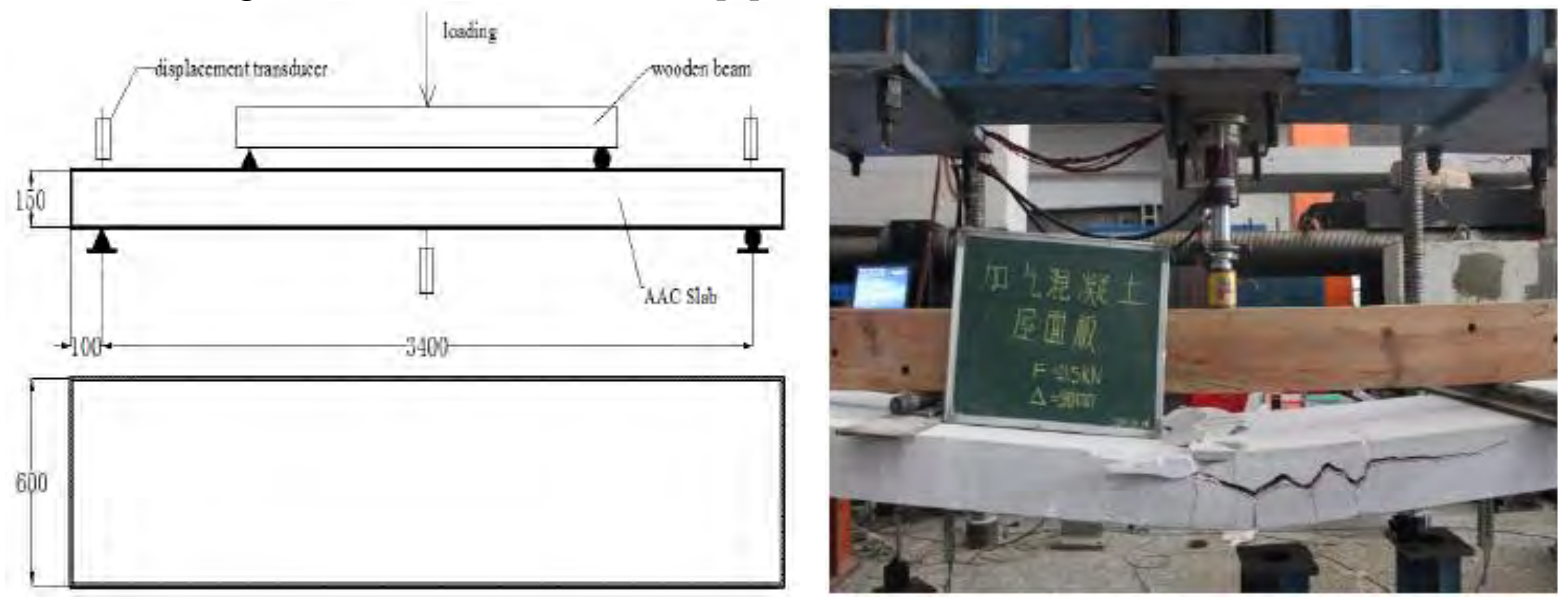

Fig. 3 The Set-up of Bending Test

\section{Results and Discussion}

\section{Phenomena and Damage Characteristics}

It was observed from Fig.4 that when the load was small, the load-deflection curves were basically linear. As the vertical load increased to $30 \% \sim 40 \%$ of the ultimate load, initial cracks appeared in the central parts of panel and the cracking load is nearly up to $6 \mathrm{kN}$. With increasing loading, several inclined flexural-shear cracks are found to form in the flexure-shear zone and then extend towards to the loading point as the Fig. 5 shows. When the load dropped to $85 \%$ of the ultimate load, more crushing and falling phenomena appeared in AAC panels, indicating that the 
panels had lost bearing capacity. The maximum crack width was about $5 \mathrm{~mm}$. Meanwhile, a silvery "clap" sound was heard as the AAC panels damaged [5]. After unloading, the inclined cracks cannot be completely closed.

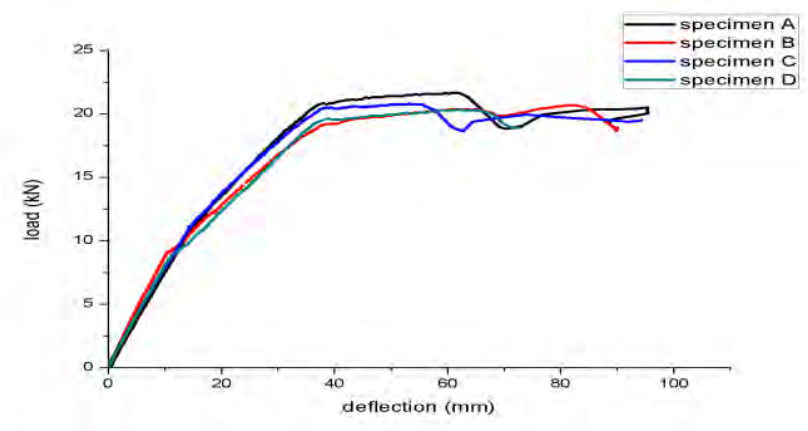

Fig. 4 The Load-deflection Curves

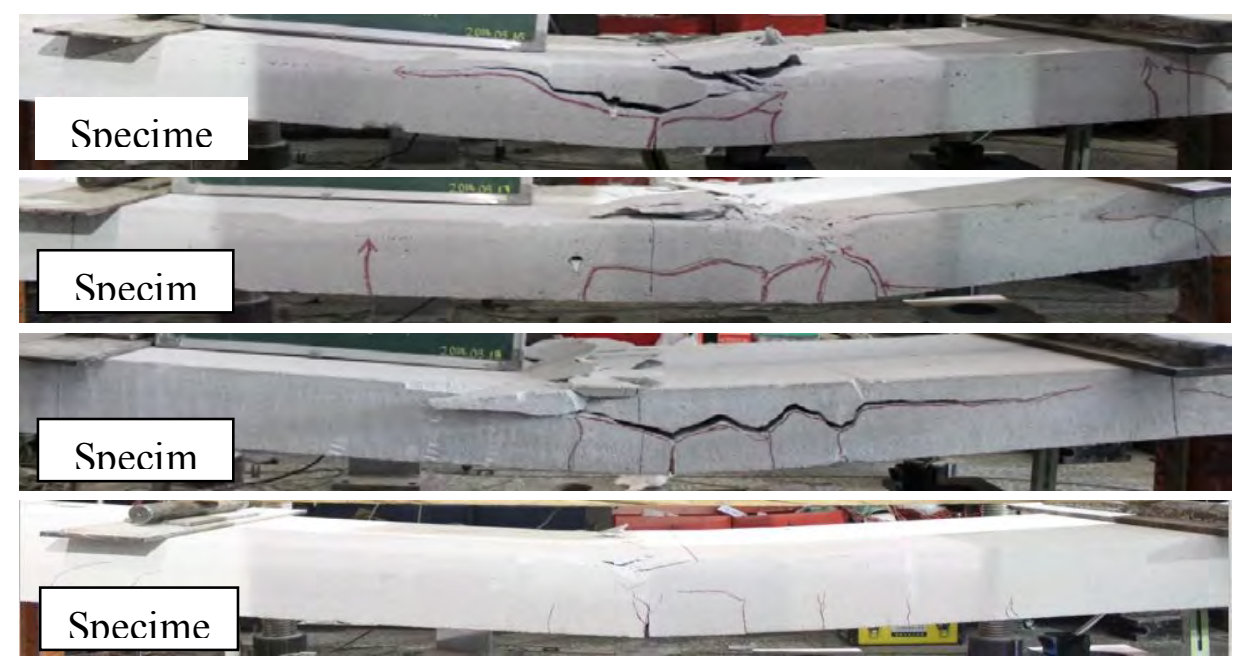

Fig. 5 The Crack Pattern

Nominal capacity is computed by assuming plane sections; tensile reinforcement is assumed to be yielded; the stress in compressive reinforcement is computed based on its strain and its stress-strain behavior [6]. The values of the measured ultimate load, cracking load, deflection and failure mode of specimens are listed in Tab.2.

Tab. 2 Information of Specimens

\begin{tabular}{|c|c|c|c|l|}
\hline $\begin{array}{c}\text { Specimen } \\
\text { no. }\end{array}$ & $\begin{array}{l}\text { Ultimate Load } \\
(\mathbf{k N})\end{array}$ & $\begin{array}{l}\text { Cracking Load } \\
(\mathbf{k N})\end{array}$ & $\begin{array}{l}\text { Deflection } \\
(\mathbf{m m})\end{array}$ & Failure Mode \\
\hline A & 21.56 & 10.37 & 95.21 & $\begin{array}{l}\text { bending-shear } \\
\text { failure }\end{array}$ \\
\hline B & 20.67 & 10.12 & 89.83 & $\begin{array}{l}\text { bending-shear } \\
\text { failure }\end{array}$ \\
\hline C & 20.83 & 9.96 & 94.15 & $\begin{array}{l}\text { bending-shear } \\
\text { failure }\end{array}$ \\
\hline D & 20.26 & 9.23 & 72.82 & $\begin{array}{l}\text { bending-shear } \\
\text { failure }\end{array}$ \\
\hline
\end{tabular}

\section{The Performance on the Bond Behavior between AAC and Reinforcement Cage}

Obviously, it could be seen that a slip point appeared from Fig. 6, suggesting that the bond behavior between AAC and reinforcing bar was so poor. Soon afterwards, the result of poor performance on the bond behavior was analyzed. Bond and development requirements for steel wire 
cages embedded in AAC are quite different from those for conventional concrete. Because the steel wire cage has a corrosion-resistant coating, the bond strength between the coated wire and the AAC itself is negligible.
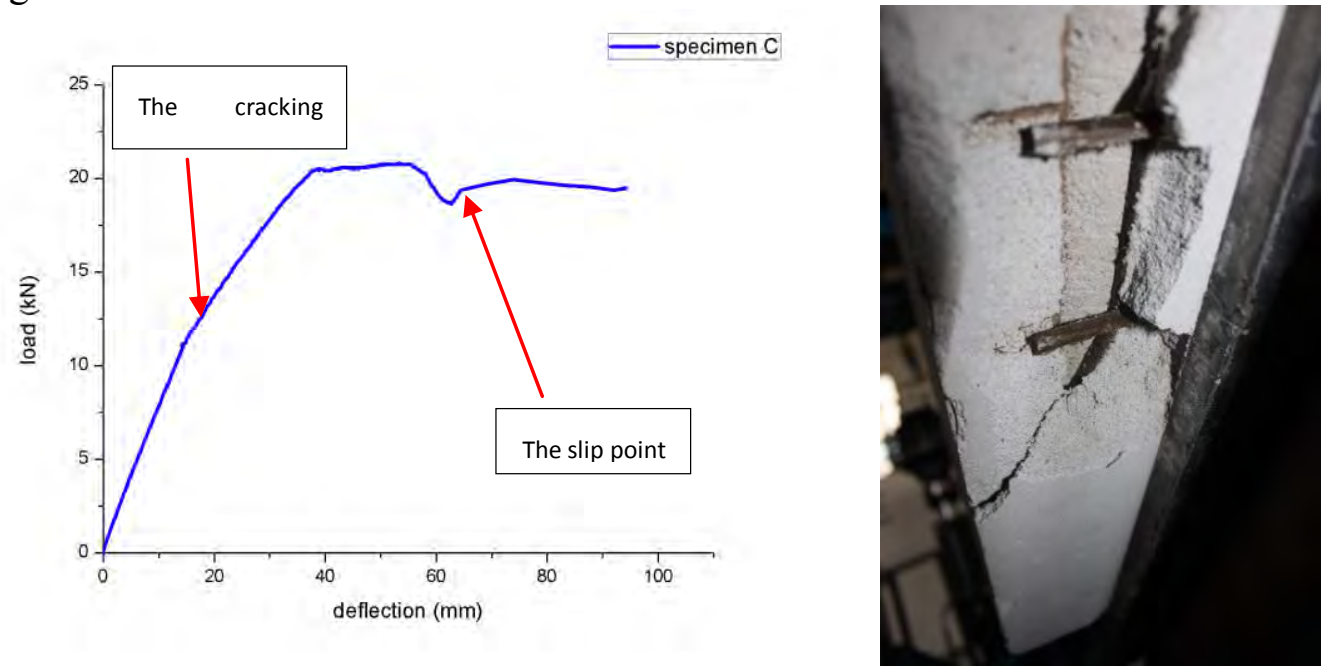

Fig. 6 The Slippage of Longitudinal Reinforcement

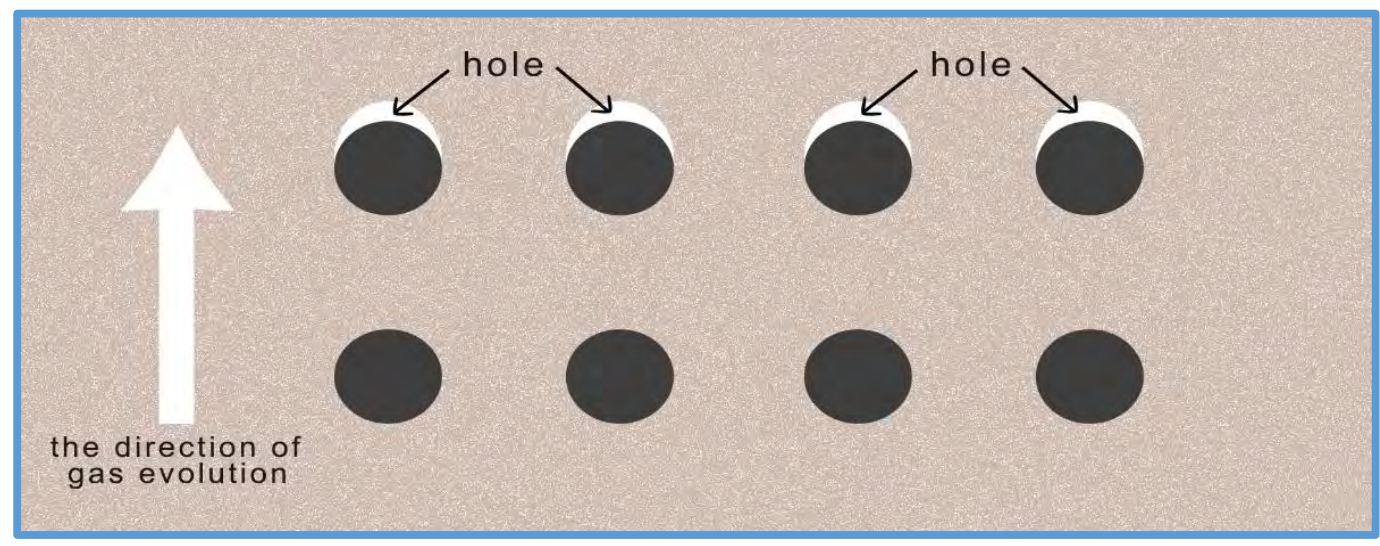

Fig. 7 The Bad Fluidity of Slurry

It is an obvious fact that the Slippage of longitudinal reinforcement are not permitted, which is supposed to affect the Mechanical Performance of AAC panels. Making an adjustment of corrosion-resistant coating is the first and direct step towards changing the poor bond. Besides, improving the fluidity of slurry is an effective means to change the bad bond behavior between AAC and steel wire [7].

\section{Summary}

Care should be taken when AAC roof panels with long span get access to shear failure. This research was aimed at giving impetus to the industrialized residences in the long run and the following conclusions were drawn from the test result;

1) The panels were tested under four-point bending to investigate their strength and the load-carrying capacity of AAC panels can meet the requirements of the roof panel.

2) The cracking load as a percentage of the maximum load ranged from $30 \%$ to $50 \%$ and is, on average, approximately $40 \%$ of the failure load.

3) The Slippage of longitudinal reinforcement are not permitted, which is supposed to affect the Mechanical Performance of AAC panels

4) Making an adjustment of corrosion-resistant coating and improving the fluidity of slurry both are effective means to change the bad bond. 
The study in this paper can provide a reliable experimental basis for further analysis and engineering application of $\mathrm{AAC}$ roof panels in the future.

\section{Acknowledgement}

The authors gratefully acknowledge funding and support provided by Beijing Municipal Commission of Housing and Urban-Rural Development. The materials were donated by JINYU, whose support was gratefully acknowledged. Helps received from staffs and students at the laboratory were also greatly acknowledged.

\section{References}

[1]Caijun S, Fouad HF. Autoclaved Aerated Concrete-properties and structural design. American Concrete Institute; 2005. Special Publication 226.

[2]Dembowski J. A Study of the material properties and structural behavior of Plain and Reinforced AAC components. M.S. thesis. CCEE Department, University of Alabama at Birmingham; 2001.

[3] Snow C. A comprehensive study of the material properties and structural behavior of AAC products. M.S. thesis. CCEE Department, University of Alabama at Birmingham; 1999.

[4]Yanmin Yang and Hao Zhang:,Experimental study on flexural behavior of all-lightweight aggregate concrete beams and slabs ${ }^{\mathrm{ee}}$, In „Key engineering materials ${ }^{\mathrm{ee}}$, Vol.517, Switzerland,2012, $51-62$.

[5]Wittman F H. Autoclaved Aerated Concrete-Properties, Testing and Design (RILEM Recommended Practice) [M]. Spon Press, London, UK, 1993.

[6]JGJ17-1984. Technical Specification of Autoclaved Aerated Concrete[S]. China Architecture and Building Press, Beijing, China, 2008 (in Chinese).

[7]ACI 523.4R-09. Guide for Design and Construction with Autoclaved Aerated Concrete Panels. American Concrete Institute; 2009. 